\title{
Polysomnograph Chart View by Patients: A New Educational Strategy to Improve CPAP Adherence in Sleep Apnea Therapy
}

\author{
Vito Antonio Falcone MD, Mario Francesco Damiani MD, Vitaliano Nicola Quaranta MD, \\ Alberto Capozzolo MD, and Onofrio Resta MD
}

\begin{abstract}
BACKGROUND: CPAP is currently the treatment of choice for obstructive sleep apnea syndrome, but therapy adherence is poor. Many educational trials have been proposed to increase CPAP adherence. We tested the hypothesis that polysomnograph chart viewing by patients would improve CPAP adherence. METHODS: A controlled parallel group study was performed with 206 newly diagnosed obstructive sleep apnea syndrome patients, randomized into 2 groups $(n=103$ each): standard support group, and educational support group. Each educational support group subject viewed 2 consecutive polysomnograms on the computer screen: the first recorded during a standard diagnostic overnight polysomnography, and the second during a full-night polysomnography with nasal CPAP. The subject's attention was drawn only to the flow and oxyhemoglobin saturation curves. Clinical outcomes were assessed via polysomnography at CPAP initiation and after 1, 3, and 12 months. RESULTS: After 12 months of CPAP, $76 \%$ of the educational support group and $52 \%$ of the standard support group returned for a follow-up visit $(P<.001)$. Statistical significance had already been reached after 1 and 3 months. Moreover, CPAP use (measured as hours of use per night) was higher in the educational support group at each control visit. CONCLUSIONS: Polysomnograph chart viewing by obstructive sleep apnea patients can increase CPAP adherence, as evaluated by rate of return for the follow-up visit and mean nightly CPAP use. Key words: CPAP; adherence; obstructive sleep apnea; behavioral interventions; patient education. [Respir Care 2014;59(2):193-198. () 2014 Daedalus Enterprises]
\end{abstract}

\section{Introduction}

Obstructive sleep apnea (OSA) is characterized by recurrent episodes of upper-airway obstruction during sleep, resulting in chronic intermittent hypoxia, sleep fragmentation, and daytime sleepiness. ${ }^{1}$ OSA is present in as many as $2 \%$ of females and $4 \%$ of males in the general population, ${ }^{2}$ and is burdened with substantial associated morbidity and mortality. ${ }^{3} \mathrm{CPAP}$ is the primary treatment for OSA syndrome,${ }^{4}$ and normalizes sleep architecture, reduces day-

\footnotetext{
The authors are affiliated with the Institute of Respiratory Disease, Università Degli Studi di Bari Aldo Moro, Bari, Italy.

The authors have disclosed no conflicts of interest.

Correspondence: Vito Antonio Falcone MD, Policlinico - Pneumologia, Università Degli Studi di Bari Aldo Moro, Piazzale Giulio Cesare 1, Bari 70124 Italy. E-mail: va.falcone13@gmail.com.
}

DOI: $10.4187 /$ respcare.02491 time sleepiness, improves daily function, decreases the risk of automobile accidents, improves quality of life, ${ }^{5}$ and decreases blood pressure and other cardiovascular events. ${ }^{6}$ Unfortunately, the data in the literature regarding CPAP adherence are not so encouraging. ${ }^{7,8}$ Current evidence suggests that only $61-69 \%$ of those prescribed CPAP adhere to it. ${ }^{9}$ Several studies tried to determine the percentage of patients who adhere to CPAP, and the estimated range is 46-80\%.7,9-14 Perhaps many people mistakenly believe that CPAP use will cure their sleep breathing disorder, at which time they can discontinue CPAP. ${ }^{15}$ Moreover, some patients do not consider OSA as a serious health problem, ${ }^{16}$ and have a poor perception of OSA's risks. ${ }^{17}$

Many studies have found that patients' perceptions of the benefits and health value of CPAP are related to better adherence. ${ }^{18,19}$ Education ${ }^{20,21}$ and intensive support strategies $^{22}$ improve long-term CPAP adherence. Given that the patient's awareness of the disease plays a decisive role in CPAP adherence, we tested the hypothesis that having the patients view the polysomnograph (PSG) chart would improve CPAP adherence. 


\section{Polysomnograph Chart View by Patients}

\section{Methods}

This prospective, randomized, single-blind, controlled, parallel group study was approved by the institutional review board of Bari University General Hospital, Bari, Italy, and carried out in accordance with the principles of the Helsinki Declaration. All subjects gave written informed consent prior to participation in the study.

\section{Subjects}

We enrolled 206 adult subjects ( $\geq 19$ y old) with newly diagnosed OSA (apnea-hypopnea index $\geq 15$ events/h, with or without daytime symptoms). We excluded patients who had COPD or any global respiratory failure, central sleep apnea syndrome, previous diagnosis of congestive heart failure or cardiomyopathy, any chronic neurological disorder, or any severe mental or psychological impairment. All the subjects lived within $30 \mathrm{~km}$ of Bari. Randomization was via predetermined balanced blocks, generated by tossing a coin. The subjects were blinded to the group to which they were allocated.

\section{Study Design}

Subjects underwent standard diagnostic overnight PSG (E Series System, Compumedics, Victoria, Australia). The diagnosis night was followed directly by a second full-night PSG with nasal CPAP with manual titration. ${ }^{23}$ Then the subjects were randomly allocated to the standard support group $(n=103)$ or the educational support group $(n=103)$.

In the standard support group a sleep medicine physician gave each subject a full explanation of the need for and benefits of CPAP. This explanation required $\leq 10 \mathrm{~min}$. Prior to CPAP titration the subjects received education from a nurse regarding operation of the CPAP machine and mask placement, and a 20-min period of auto-CPAP exposure during the afternoon, for CPAP acclimatization.

In the educational support group, as in the standard support group, all subjects received education about OSA and its risks. In addition, each educational support group subject viewed, simultaneously, on the computer screen, the first $10 \mathrm{~min}$ of the rapid-eye-movement phase of both the PSG charts: from the diagnosis PSG night (Fig. 1) and the CPAP titration PSG night (Fig. 2), and received explanations of the charts from a sleep medicine physician, to emphasize the PSG signs of apnea-hypopnea and the disappearance of those signs with CPAP. We drew the subject's attention only to the flow and oxyhemoglobin saturation curves. This standardized procedure, which took $\leq 5 \mathrm{~min}$, was performed with all the educational support group subjects, by one of the 3 responsible sleep physicians in charge.

In both groups, 3 follow-up visits were performed, at 1, 3 , and 12 months after CPAP initiation. At diagnosis and at each follow-up we measured the Epworth Sleepiness

\section{QUICK LOOK}

\section{Current knowledge}

CPAP is commonly used for the treatment of obstructive sleep apnea, but adherence to CPAP is poor because of discomfort and cumbersome application. Education programs to improve adherence have had varying results.

\section{What this paper contributes to our knowledge}

Patients who, with a clinician's guidance, reviewed their polysomnography $\mathrm{S}_{\mathrm{pO}_{2}}$ and flow curves were more likely to return for their follow-up appointments and had better CPAP adherence at 12 months.

Scale score. ${ }^{24}$ At each follow-up visit we calculated the retention rate (calculated as the number of subjects who returned for follow-up divided by the total number of subjects) and downloaded the CPAP use data from the CPAP device. Any problems with CPAP treatment were addressed, and the CPAP data were reviewed with the subject, without emphasizing the achievements. Subjects who did not return for a follow-up visit were considered nonadherent and dropped-out the study, so the Epworth Sleepiness Scale scores and CPAP use data in the Results section are only for the adherent CPAP users.

\section{Statistical Analysis}

The analyses were on an intention-to-treat basis. Data are presented as mean \pm SD unless otherwise indicated. Differences between the groups were analyzed with the Student $t$ test for independent samples for normally distributed variables, or the Mann-Whitney $\mathrm{U}$ test for nonnormally distributed variables. The chi-square test was used to compare proportions between groups. $P<.05$ was considered significant.

\section{Results}

Figure 3 shows the study flow chart. The Table shows the cohort's baseline characteristics. There were no significant baseline differences between the 2 groups. Body mass index and neck and waist circumference did not change significantly during the study. During the CPAP PSG night the apnea-hypopnea index, oxygen desaturation index, and total sleep time with oxyhemoglobin saturation below $90 \%$ improved significantly in both groups and to a similar degree (data not shown).

\section{Retention Rate}

After 1 month of CPAP, 93\% of the educational support group subjects and $78 \%$ of the standard support group 


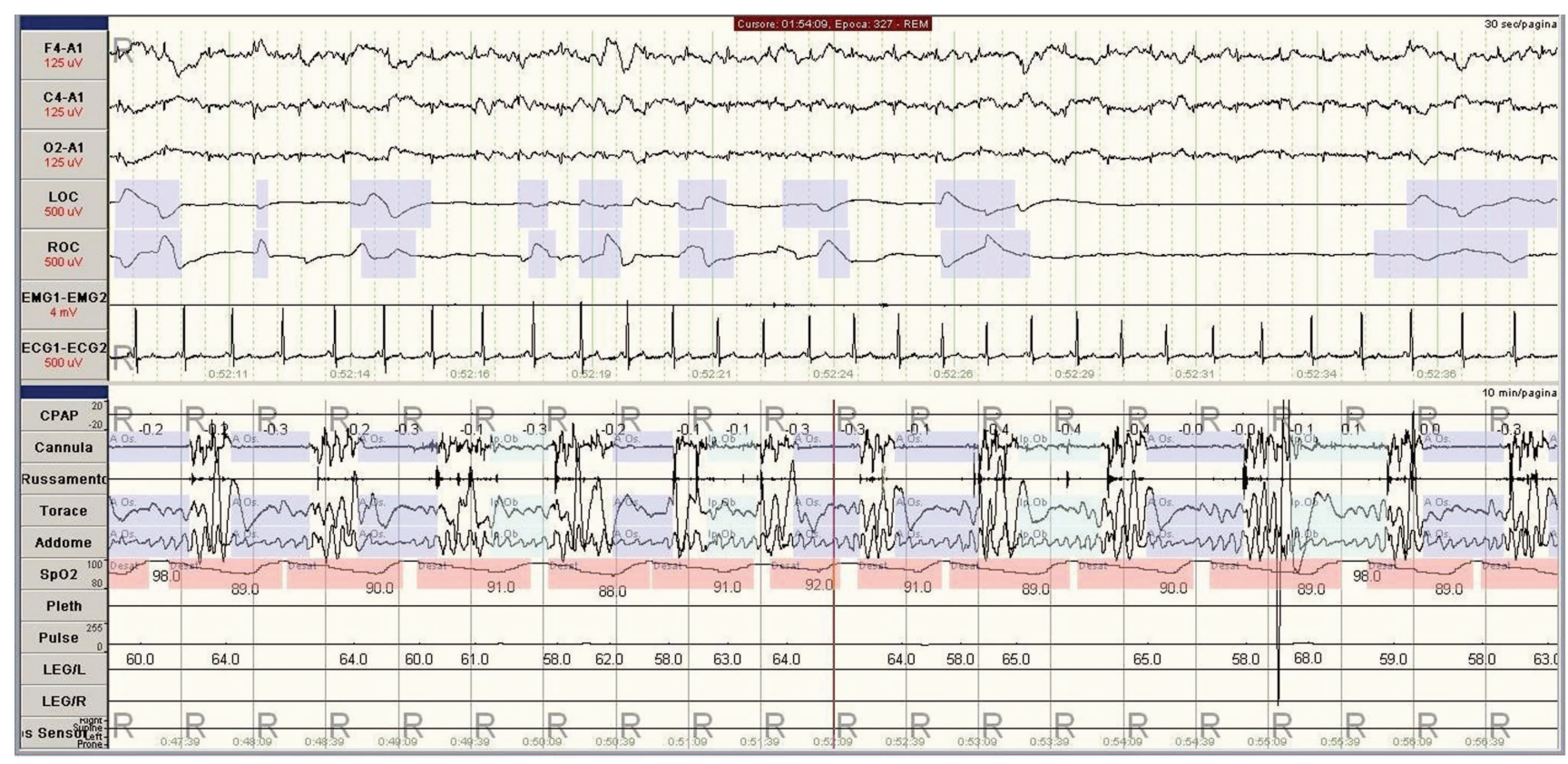

Fig. 1. Example polysomnography chart of $10 \mathrm{~min}$ of the rapid-eye-movement phase during the obstructive sleep apnea diagnosis night.

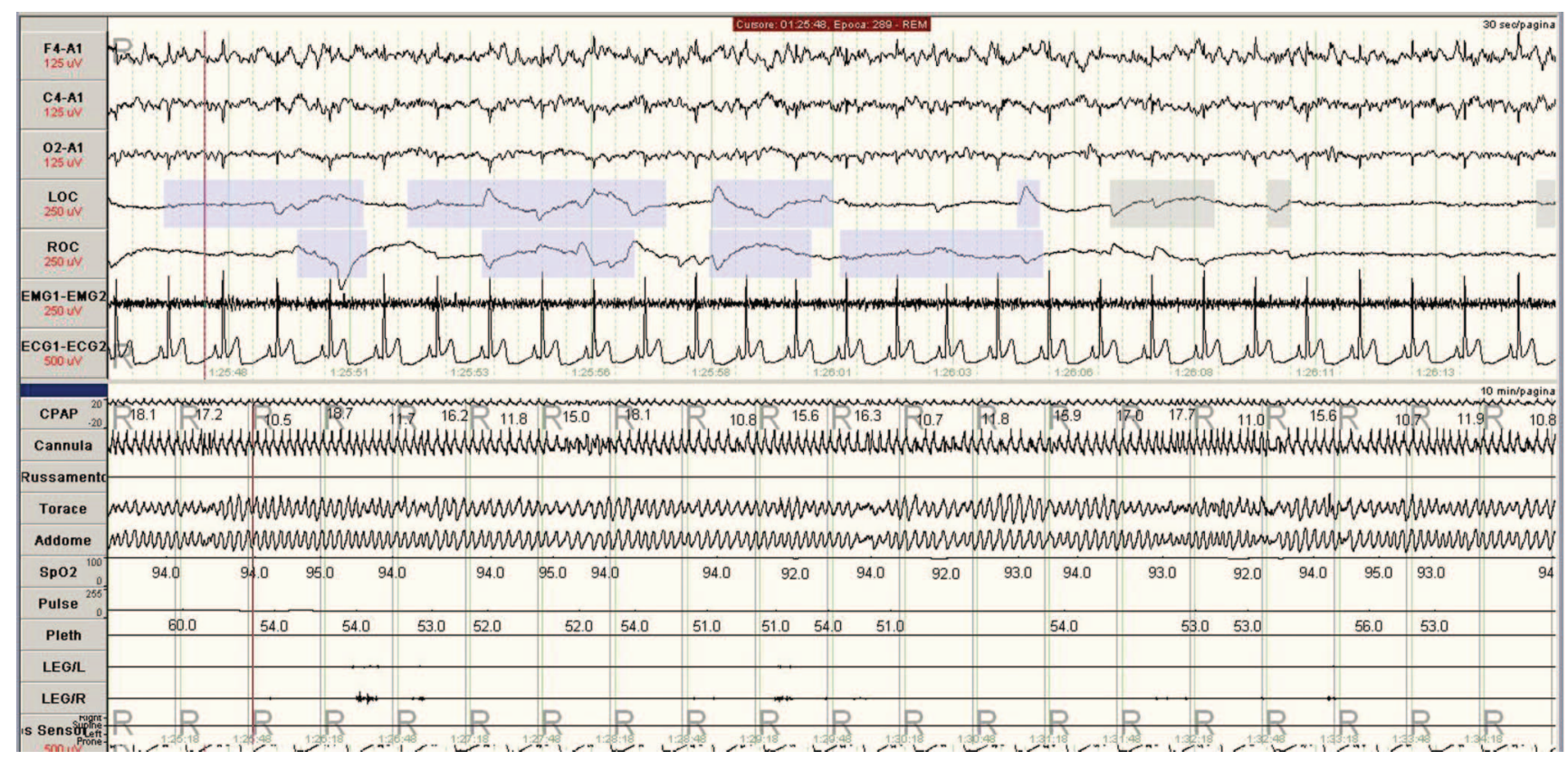

Fig. 2. Example polysomnography chart of $10 \mathrm{~min}$ of the rapid-eye-movement phase during the CPAP titration night.

subjects returned for follow-up (chi-square $=9.98$, $P=.002$ ). At 3 months, $87 \%$ of the educational support group subjects came to the follow-up appointment, versus $69 \%$ of the standard support group subjects (chisquare $=10.26, P=.002$ ). At 12 months, $77 \%$ of the educational support group came to the follow-up appointment, versus $52 \%$ of the standard support group subjects (chi-square $=13.26, P<.001)($ Fig. 4$)$.

\section{CPAP Use}

At 1 month the educational support group had higher mean CPAP use: $5.20 \pm 1.29 \mathrm{~h} /$ night vs $4.24 \pm 0.76 \mathrm{~h} /$ night $(P=.008)$. At 3 and 12 months the significant differences in CPAP use between the 2 groups persisted: $5.25 \pm 0.91 \mathrm{~h} / \mathrm{night}$ versus $4.12 \pm 0.57 \mathrm{~h} / \mathrm{night}(P=.007)$, and $5.24 \pm 0.85 \mathrm{~h} / \mathrm{night}$ versus $4.02 \pm 0.37 \mathrm{~h} / \mathrm{night}$ $(P=.005)$, respectively (Fig. 5). 


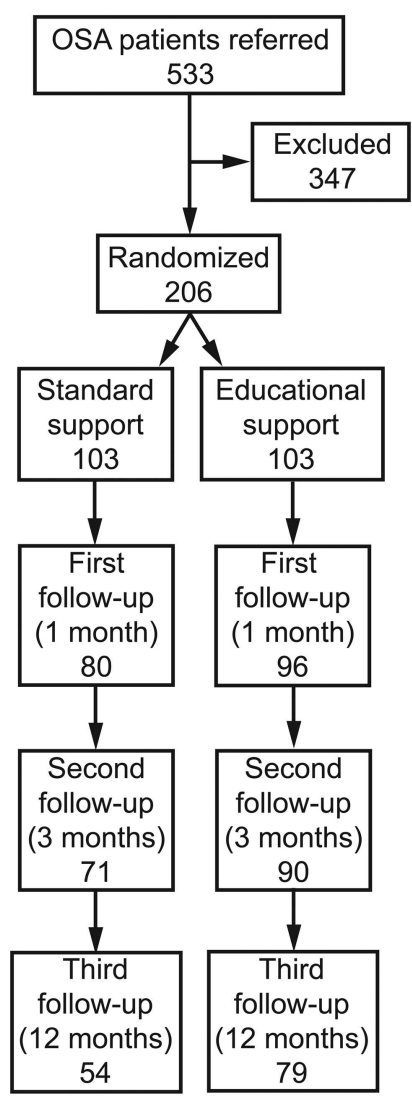

Fig. 3. Flow chart. OSA = obstructive sleep apnea.

Table. Subject Characteristics at Baseline

\begin{tabular}{lccc}
\hline \hline & $\begin{array}{c}\text { Educational } \\
\text { Support } \\
\text { Group } \\
(n=103)\end{array}$ & $\begin{array}{c}\text { Standard } \\
\text { Support } \\
\text { Group } \\
(n=103)\end{array}$ & $P$ \\
\hline Age, y & $60.75 \pm 8.6$ & $61.85 \pm 7.1$ & .35 \\
Male, \% & 77 & 73 & .52 \\
Female, \% & 23 & 27 & .41 \\
Body mass index, $\mathrm{kg} / \mathrm{m}^{2}$ & $33.9 \pm 7.1$ & $30.2 \pm 5.1$ & .20 \\
Apnea-hypopnea index & $56.0 \pm 5.2$ & $52 \pm 6.4$ & .11 \\
Oxygen desaturation index & $40.1 \pm 4.1$ & $37 \pm 5.8$ & .22 \\
Total sleep time with $\mathrm{S}_{\mathrm{pO}_{2}}<90 \%$ & $15.0 \pm 5.4$ & $16.1 \pm 6.7$ & .48 \\
Neck circumference, cm & $43.3 \pm 2.0$ & $43.0 \pm 2.0$ & .55 \\
Waist circumference, cm & $108.0 \pm 8.6$ & $110.2 \pm 7.8$ & .45 \\
Epworth Sleepiness Scale score & $11.2 \pm 1.9$ & $11.1 \pm 1.7$ & .53 \\
& & & \\
\hline Values are mean \pm SD. & & & \\
\hline
\end{tabular}

At 1 month, 94\% of the educational support group and $69 \%$ of the standard support group had used their CPAP $>4 \mathrm{~h} /$ night for $>70 \%$ of all the nights (chi-square $=13.06$, $P<.001)$. At 3 and 12 months that significant difference persisted: $97 \%$ versus $71 \%$ (chi-square $=14.79, P<.001$ ), and $97 \%$ versus $74 \%$ (chi-square $=12.66, P<.001$ ), respectively (Fig. 6).

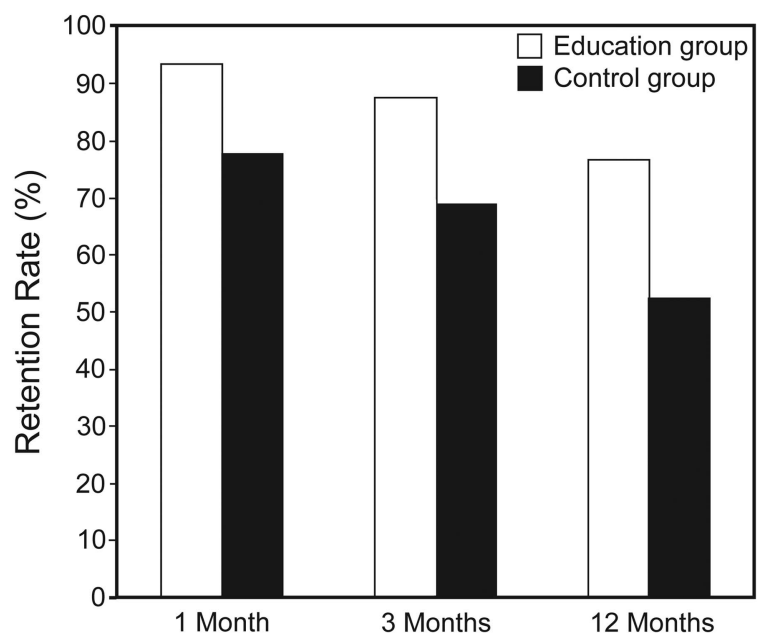

Fig. 4. Retention at follow-up visits at 1, 3, and 12 months.

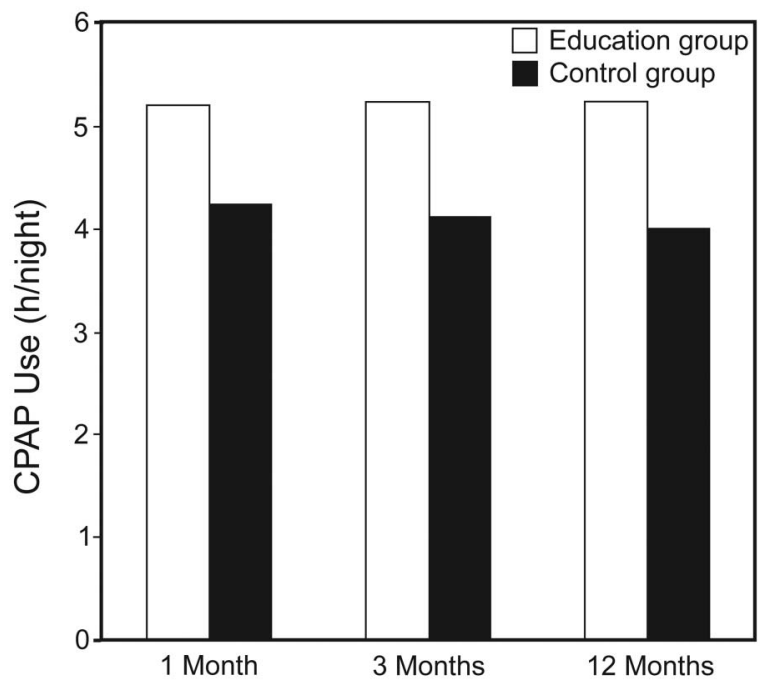

Fig. 5. Mean hours of nightly CPAP use at 1, 3, and 12 months.

The mean Epworth Sleepiness Scale score was significantly and similarly reduced at 1 month in both groups: $4.37 \pm 0.30$ in the standard support group, and $4.30 \pm 0.20$ in the educational support group. At 3 and 12 months the mean Epworth Sleepiness Scale score remained substantially stable, and there were no significant differences between the groups: at 3 months $4.04 \pm 0.23$ vs $4.14 \pm 0.31$, at 12 months $3.30 \pm 0.28$ vs $3.10 \pm 0.35$.

\section{Discussion}

Our most important finding is that a significantly higher percentage of educational support group subjects returned for follow-up at 1, 3, and 12 months. This higher retention rate suggests that knowledge and awareness of OSA and its risks may be a key aspect of CPAP adherence. Some previous studies demonstrated the importance of education 


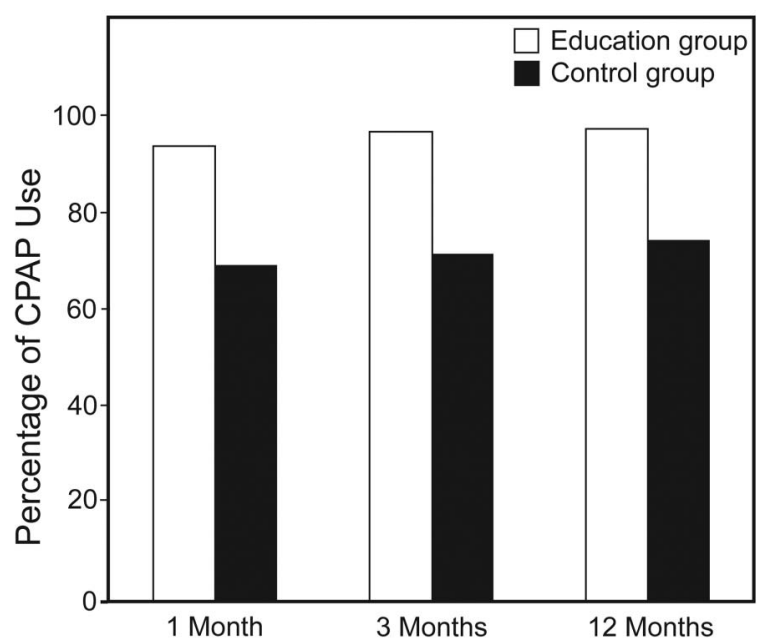

Fig. 6. Percentages of subjects who used their CPAP machines for $>4 \mathrm{~h} / \mathrm{night}$ for $>70 \%$ of all the nights, at 1,3 , and 12 months.

in CPAP adherence,,$^{21,22,25-27}$ but to our knowledge this is the first long-term study in which subjects viewed their own PSG charts with and without CPAP. Ninety-three percent of the subjects who viewed their PSG charts returned for follow-up at 1 month, and $76 \%$ returned at 12 months. There are 2 possible explanations for the difference in retention. First, viewing the PSG chart is certainly of paramount importance in realizing the pathophysiological changes and importance of OSA; indeed, even a more detailed explanation of OSA and/or CPAP cannot disregard the visual experience of the classic PSG signs of apnea/hypopnea, and their disappearance with CPAP. Second, it is conceivable that viewing the PSG charts has an important psychological impact, increasing the patient's awareness of their condition and therefore their motivation to adhere to CPAP. In support of this, in the recent study by Nadeem et $\mathrm{al}^{28}$ the subjects who viewed only the pathological PSG chart (without viewing the with-CPAP PSG chart that showed the resolution of the OSA events) did not improve CPAP adherence, compared to the control arm.

At every follow-up visit we observed higher CPAP use in the educational support group: mean $5 \mathrm{~h} /$ night versus $4 \mathrm{~h} /$ night. On the other hand, although a standard criteria to define the optimal nightly duration of CPAP use has not been established, ${ }^{26,29}$ some authors consider $4 \mathrm{~h} /$ night for $70 \%$ of nights acceptable. ${ }^{7,23,29,30}$ Using that definition we found better adherence in the educational support group (see Fig. 6).

Several randomized controlled trials have found significant clinical improvement with even the relatively low levels of CPAP use we found in our standard support group. $^{31,32}$ This was confirmed in our study since we observed that CPAP treatment reduced the Epworth Sleepiness Scale score in both groups to a similar extent.
Education studies regarding CPAP adherence have often included multiple simultaneous interventions ("packages"). ${ }^{18}$ In the study by Hoy et $\mathrm{al}^{22}$ the subjects in the educational support group received home nursing, a 3-night CPAP trial, and educational support. In the study by Damjanovic et al ${ }^{27}$ the intensive support included optimizing the equipment, such as the correct use of humidifiers and mask fit, together with counseling and educational support. However, in the present study the educational support was based on a single and brief intervention in order to assess its specific contribution to CPAP adherence, avoiding potential confounding factors.

Here some limitations need to be taken into account. First, the expression "retention rate" should be used with caution. In fact, the design of this study does not allow us to know whether all the subjects who did not return for follow-up were really non-adherent to CPAP. On the other hand, it is likely that subjects who do not return to clinic are not adherent, since several insurance companies require proof of periodic clinic attendance for coverage of CPAP machine rental, and non-adherent subjects lose the use of the machine. ${ }^{21}$ Retention rate has been considered a key indicator of CPAP adherence by various researchers as well. ${ }^{21,27,30}$ Finally, in our study, CPAP adherence was not reinforced during the follow-up visits, so as not influence the outcome.

Second, only reduced daytime sleepiness was considered as a clinical outcome, and it is possible that there were significant differences in other symptoms, quality of life, cognitive function, and apnea-hypopnea index. However, daytime sleepiness is considered a key factor in the clinical evaluation of OSA patients, ${ }^{33}$ and we considered the mean nightly CPAP use adequate in both groups. These considerations to some extent counterbalance this limitation.

This study did not include a cost-benefit analysis. However, this educational procedure does not entail any additional cost except for adding $5 \mathrm{~min}$ to the standard protocol. Hence, it may be easily reproduced in any sleep medicine center.

To overcome the potential limit of the patients' ability to interpret the PSG chart, we focused their attention only on the flow and oxyhemoglobin saturation curves.

The present study included only subjects with moderate to severe OSA, so our results cannot be applied to patients with mild OSA.

\section{Conclusions}

We have demonstrated that having the patient view the PSG charts from both the OSA diagnosis night and the CPAP titration night can improve CPAP adherence, as evaluated by follow-up-retention rate and mean nightly CPAP use.

\section{REFERENCES}

1. Olson EJ , Park JG, Morgenthaler TI. Obstructive sleep apnea-hypopnea syndrome. Prim Care 2005;32(2):329-359. 


\section{Polysomnograph Chart View by Patients}

2. Young T, Palta M, Dempsey J, Skatrud J, Weber S, Badr S. The occurrence of sleep-disordered breathing among middle-aged adults. N Engl J Med 1993;328(17):1230-1235.

3. Kokturk O, Ciftci TU, Mollarecep E, Ciftci B. Elevated C-reactive protein levels and increased cardiovascular risk in patients with obstructive sleep apnea syndrome. Int Heart J 2005;46(5):801-809.

4. Marrone O, Resta O, Salvaggio A, Giliberti T, Stefano A, Insalaco G. Preference for fixed or automatic CPAP in patients with obstructive sleep apnea syndrome. Sleep Med 2004;5(3):247-251.

5. Avlonitou E, Kapsimalis F, Varouchakis G, Vardavas CI, Behrakis P. Adherence to CPAP therapy improves quality of life and reduces symptoms among obstructive sleep apnea syndrome patients. Sleep Breath 2012;16(2):563-569.

6. Gay P, Weaver T, Loube D, Iber C. Evaluation of positive airway pressure treatment for sleep related breathing disorders in adults. Sleep 2006;29(3):381-401.

7. Kribbs NB, Pack AI, Kline LR, Smith PL,Schwartz AR, Schubert, et al. Objective measurement of patterns of nasal CPAP use by patients with obstructive sleep apnea. Am Rev Respir Dis 1993;147(4):887-895.

8. Engleman HM, Martin SE, Douglas NJ. Compliance with CPAP therapy in patients with the sleep apnoea/hypopnoea syndrome. Tho$\operatorname{rax}$ 1994;49(3):263-266.

9. McArdle N, Devereux G, Heidarnejad H, Engleman HM, Mackay TW, Douglas NJ. Long-term use of CPAP therapy for sleep apnea/ hypopnea syndrome. Am J Respir Crit Care Med 1999;159(4 Pt 1):1108-1114

10. Waldhorn RE, Herrick TW, Nguyen MC, O'Donnell AE, Sodero J, Potolicchio SJ. Long-term compliance with nasal continuous positive airway pressure therapy of obstructive sleep apnea. Chest 1990; 97(1):33-38.

11. Popescu G, Latham M, Allgar V, Elliott MW. Continuous positive airway pressure for sleep apnoea/hypopnoea syndrome: usefulness of a 2 week trial to identify factors associated with long term use. Thorax 2001;56(9):727-733.

12. Hui DS, Choy DK, Li TS, Ko FW, Wong KK, Chan JK, Lai CK. Determinants of continuous positive airway pressure compliance in a group of Chinese patients with obstructive sleep apnea. Chest 2001;120(1):170-176.

13. Hoffstein V, Viner S, Mateika S, Conway J. Treatment of obstructive sleep apnea with nasal continuous positive airway pressure: patient compliance, perception of benefits, and side effects. Am Rev Respir Dis 1992;145(4 pt 1):841-845.

14. Rolfe I, Olson LG, Saunders NA. Long-term acceptance of continuous positive airway pressure in obstructive sleep apnea. Am Rev Respir Dis 1991;144(5):130-133.

15. Smith CE, Mayer LS, Metsker C, Voelker M, Baldwin S, Whitman RA, Pingleton SK. Continuous positive airway pressure: patients' and caregivers' learning needs and barriers to use. Heart Lung 1998; 27(2):99-108.

16. Tyrrell J, Poulet C, Pe Pin JL, Veale D. A preliminary study of psychological factors affecting patients' acceptance of CPAP therapy for sleep apnoea syndrome. Sleep Med 2006;7(4):375-379.

17. Weaver TE, Maislin G, Dinges G, Younger J, Cantor C, McCloskey S, Pack AI. Self-efficacy in sleep apnea: instrument development and patient perceptions of obstructive sleep apnea risk, treatment benefit, and volition to use continuous positive airway pressure. Sleep 2003;26(6):727-732.

18. Engleman HM, Wild MR. Improving CPAP use by patients with the sleep apnoea/hypopnoea syndrome (SAHS). Sleep Med Rev 2003; 7(5):81-99.

19. Wild MR, Engleman HM, Douglas NJ, Espie CA. Can psychological factors help us to determine adherence to CPAP? A prospective study. Eur Respir J 2004;24(3):461-465.

20. Golay A, Girard A, Grandin S, Metrailler JC, Victorion M, Lebas P et al. A new educational program for patients suffering from sleep apnea syndrome. Patient Educ Counsel 2006;60(2):220-227.

21. Wiese HJ, Boethel C, Phillips B, Wilson JF, Peters J, Viggiano T . CPAP compliance: video education may help! Sleep Med 2005;6(2): 171-174.

22. Hoy CJ, Vennelle M, Kingshott RN, Engleman HM, Douglas NJ. Can intensive support improve continuous positive airway pressure use in patients with the sleep apnea/hypopnea syndrome? Am J Respir Crit Care Med 1999;159(4 Pt 1):1096-1100.

23. Insalaco G, Fanfulla F, Benassi F, Dal Farra F, De Michelis C, Patruno V et al. Raccomandazioni per la diagnosi e cura dei Disturbi Respiratori nel Sonno. Milano: Edizioni AIPO Ricerche 2011;85-87. Article in Italian.

24. Vignatelli L, Plazzi G, Barbato A, Ferini-Strambi L, Manni R, Pompei F, D'Alessandro R, GINSEN. Italian version of the Epworth sleepiness scale: external validity. Neurol Sci 2003;23(6):295-300.

25. Aloia M, Arnedt JT, Stepnowsky C, Hecht J, Borrelli B. Predicting treatment adherence in obstructive sleep apnea using principles of behavioral change. J Clin Sleep Med 2005;1(4):346-353.

26. Fletcher EC, Luckett RA. The effect of positive reinforcement on hourly compliance in nasal continuous positive airway pressure users with obstructive sleep apnea. Am Rev Respir Dis 1991;143(5 Pt 1):936-941.

27. Damjanovic D, Fluck A, Bremer H, Muller-Quernheim J, Idzko M, Sorichter S. Compliance in sleep apnoea therapy: influence of home care support and pressure mode. Eur Respir J 2009;33(4):804-811.

28. Nadeem R, Rishi MA, Srinivasan L, Copur AS, Naseem J. Effect of visualization of raw graphic polysomnography data by sleep apnea patients on compliance with CPAP therapy. Respir Care 2012;58(4): 607-613.

29. Reeves-Hoche MK, Meek R, Zwillich C. Nasal CPAP: an objective evaluation of patient compliance. Respir Crit Care Med 1999;149(1): 149-154.

30. Weaver TE, Maislin G, Dinges DF, Bloxham T, George CF, Greenberg $\mathrm{H}$ et Al. Relationship between hours of CPAP use and achieving normal levels of sleepiness and daily functioning. Sleep 2007;30(6): 711-719.

31. Engleman HM, Martin SE, Deary IJ, Douglas NJ. Effect of continuous positive airway pressure treatment on daytime function in sleep apnoea/hypopnoea syndrome. Lancet 1994;343(8897):572-575.

32. Engleman HM, Martin SE, Kingshott RN, Mackay TW, Deary IJ, Douglas NJ. Randomised, placebo controlled trial of daytime function after continuous positive airway pressure (CPAP) therapy for the sleep apnoea/hypopnoea syndrome. Thorax 1998;53(5):341-345.

33. Johns MW. Sensitivity and specificity of the multiple sleep latency test (MSLT), the maintenance of wakefulness test and the epworth sleepiness scale: failure of the MSLT as a gold standard. J Sleep Res 2000;9(1):5-11.

This article is approved for Continuing Respiratory Care Education credit. For information and to obtain your CRCE

(free to AARC members) visit www.rcjournal.com

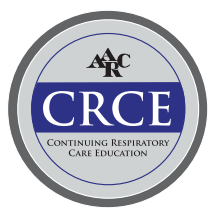

